ЛИСЕЧКО В.П., к.т.н., доцент (Український державний університет залізничного транспорту), ОБІХОД Я.Я., програміст («Soft-review», м. Київ),

ОЛЕФІРЕНКО Т.М., студентка (Український державний університет залізничного транспорту)

\title{
Дослідження імовірнісного розподілу службових сигналів в когнітивному радіо
}

У статті розглядається нейронна мережа у вигляді самоорганізаційної карти Кохонена як метод структурування сервісних сигналів стандарту IEEE 802.22. Розглянуто нейронну мережу СКК як когнітивний рівень в класифікації службових сигналів стандарту IEEE 802.22. Було побудовано імітаційну модель в середовищі розробки МАTLAB. Результат даної роботи показав, щзо СКК здатна кластеризувати складні сигнали, щзо, в свою чергу, вирішує задачу, яка була поставлена.

Ключові слова: когнітивне радіо, радіочастотний ресурс, WiMAX, LTE, нейронна мережа (НС), самоорганізаційна карта Кохонена (СКК).

\begin{abstract}
Постановка проблеми
Основною проблемою радіомовлення кінця 20 століття по теперішній час $\epsilon$ обмеженість радіочастотного ресурсу. Кількість користувачів, обсяги передачі даних зростають. Основним рішенням браку спектра зводилося, в основному, до двох способів: в організації радіоканалів (FDMA, OFDMA, CDMA і ін.) і частотного ущільнення робочих сервісів, модуляції та ін. Дані рішення знайшли свою реалізацію в таких технологіях, як WiMAX i LTE. Альтернативне вирішення даного питання запропонував Міжнародний інститут інженерів електрозв'язку (IEEE) в стандарті IEEE 802.22, який був опублікований в 2011 році. В основу стандарту лягли дослідження Джозефа Мітоли $[1,7]$, які припускали використовувати «прогалини» в частотному спектрі. Стандарт знайшов своє застосування в ДВЧ / УВЧ-діапазоні 54-862 МГц. Основною відмінністю від стандартів 4 покоління полягало у використанні когнітивних функцій таких як: використання програмно реконфігурованих радіо, механізму спільного співіснування, аналізу топологічної околиці.
\end{abstract}

\begin{tabular}{l}
\hline Мета статті \\
Мета даної статті полягає в реалізації алгоритму \\
функціонування нейронної мережі для структурування \\
робочого каналу і каналів, визначених специфікацією \\
стандарту IEEЕ802.22-1. Базова станція ініціалізує \\
робочий канал на МАС/РНY рівні і виконує певні дії з \\
використанням самооргнізаційної карти Кохонена \\
(СКК) [2] як когнітивного рівня у структуруванні \\
сигналів певних специфікацій стандарту IЕEЕ802.22-2.
\end{tabular}

() В.П. Лисечко, Я.Я. Обіход, Т.М. Олефіренко, 2015
Всі інші канали, потенційно доступні специфікацією стандарту, але які не вибрані в якості робочого або резервного каналів можуть бути класифіковані як: заборонений, операційний, резервний, канал-кандидат, захищений, класифікований. У стандарті наводяться визначення даних пріоритетів, але не наводиться конкретних алгоритмів i реалізацій для вибору робочого каналу і пріоритетів.

\section{Аналіз літератури}

У літературі [3, 4, 5, 6] описані алгоритми і методи визначення пріоритетів. Всі вони засновані на безпосередньо фізичній обробці даних і від фактичного стану такого сигналу і самого середовища передачі даних. Ніяких когнітивних функцій, таких як аналіз топології середовища, впорядкування інформації, графічної візуалізації, збереження інформації, вони не виконують [9 - 11]. Тому існує необхідність розглянути СКК як функціональний принцип дії у структуруванні.

Основна частина

Нехай на вхід когнітивної системи довільно надходить певна кількість вхідної інформації:

$$
\begin{aligned}
& F\left(x_{i}, x_{2}, \ldots, x_{m}\right)=\sum_{z=1}\left(a_{z} S_{z}\left(x_{i}, x_{2}, \ldots, x_{m}\right)+q_{z} C_{z}\left(x_{i}, x_{2}, \ldots, x_{m}\right)\right), \\
& s_{z}\left(x_{1}, x_{2}, \ldots . x_{m}\right)=\sin \left(\sum_{j=1}^{n} \omega_{j} k_{z j} x_{j}\right)-\text { синусна частина } \\
& \text { Z-ï гармоніки, } \\
& C_{z}\left(x_{1}, x_{2}, \ldots x_{m}\right)=\cos \left(\sum_{j=1}^{n} \omega_{j} k_{z j} x_{j}\right)-\text { косинусна частина }
\end{aligned}
$$
Z-ї гармоніки,

$\omega_{j}$ - базова частота з незалежного фактору,

$x_{j} k_{z j}$ - частотний коефіцієнт фактора $x_{j}$ в $Z$-й гармоніці. 
Даний ряд можна задати набором поєднань деяких частотних коефіцієнтів:

$F\left(\sum_{z=1}^{l}\left(a S_{z}\left(x_{1}, x_{2}, \ldots, x_{m}\right)+q_{z} C_{z}\left(x_{1}, x_{2}, \ldots,\right)\right)+1\right), \ldots$ $\ldots, F(T+M-1)$.

Те, що лежить всередині вихідного гармонійного ряду, назвемо вибором довжини М 3 моментом початку часу $\mathrm{t} ; \mathrm{M}=\{1,2, \ldots, \mathrm{T}\}, \mathrm{t}=\{1,2, \ldots, \mathrm{T}-\mathrm{M}+1\}$. Фактично дані значення $€$ відрізком гармонійного ряду, що має точку початку відліку і довжину.

Для розрахунків перейдемо до векторного позначення вибірки

$Q_{g}^{R}=Q(q), Q(q+1) \ldots, Q(q+R-1)^{G}$

і часового ряду

$Q_{W}^{R}=(Z(1), Z(2), \ldots, Z(R))^{R}$.

Використовуючи властивість повторюватися, апроксимуємо вибірку $Q_{g}^{R}$ за допомогою вибірки $Q_{g=k}^{R}$ у вираз

$Q_{g}^{R}=\beta_{1} Q_{q-k}^{R}+\beta_{0} J^{R}+E^{R}$,

де $\beta_{1}$ і $\beta_{0}$-коефіціснти,

$J^{R}$ - одиничний вектор,

$E^{R}$ - вектор значень помилок апроксимації

Перетворюючи даний вираз, отримаємо

$\mathcal{Q}_{g}^{R}=Q_{g}^{R}=\beta_{1} Q_{q-k}^{R}+\beta_{0} J^{R}$

Розглянемо 50 довільно взятих програмнозгенерованих послідовностей, які імітують вхідний простір. Зробимо навчання за правилом Хебба [13], задавши в якості навчальної вибірки 8 довільнозгенерованих послідовностей. Правило Хебба передбачає зміни зв'язків тільки в одному напрямку, що в нашому випадку може призвести до неправильного визначення значень ваг. Щоб уникнути цього, введемо поняття згладжуючої функції $q\left(\delta_{i}\right) w_{j}$. Згладжуюча функція складається з добутку вектора синоптичних вагів $w_{j}, j$-го нейрона i позитивної скалярної функції відгуку $\delta_{i}$. Виходячи 3 [1], єдиною вимогою, що накладається на функцію $q\left(\delta_{i}\right), \quad \epsilon$ рівність нулю постійного доданка розкладання в ряд Тейлора, тобто: $q\left(\delta_{i}\right)=0$ при $\delta_{i}=0$. Тоді зміна вектора ваг $j$ - го нейрона в решітці можна виразити наступним чином:

$\Delta w_{i}=\varphi \delta_{i} x-q\left(\delta_{i}\right) w_{j}$,

де $\varphi$ - параметр швидкості навчання алгоритму,

$\varphi \delta_{i} x$ - доданок Хебба,

$q\left(\delta_{i}\right) w_{j}$ - згладжуюча функція.

Змоделюємо дану ситуацію в середовищі MATLAB [12]. Мережа навчалася із заданим циклом навчання в 1000.Така структура показана на рис. 1. Початкові значення ваг, зсувів і параметрів активності нейронів надані в табл. 1 .

Таблиця 1

Основні параметри мережі

\begin{tabular}{|c|c|c|c|c|}
\hline № & $\begin{array}{c}\text { Значення } \\
\text { ваг,од. }\end{array}$ & $\begin{array}{c}\text { Значення } \\
\text { ваг,од. }\end{array}$ & Зсув, од. & $\begin{array}{c}\text { Активність, } \\
\text { од. }\end{array}$ \\
\hline 1 & 5.0000 & 2.5000 & 0.1250 & 21.7463 \\
\hline 2 & 5.0000 & 2.5000 & 0.1250 & 21.7463 \\
\hline 3 & 5.0000 & 2.5000 & 0.1250 & 21.7463 \\
\hline 4 & 5.0000 & 2.5000 & 0.1250 & 21.7463 \\
\hline 5 & 5.0000 & 2.5000 & 0.1250 & 21.7463 \\
\hline 6 & 5.0000 & 2.5000 & 0.1250 & 21.7463 \\
\hline 7 & 5.0000 & 2.5000 & 0.1250 & 21.7463 \\
\hline 8 & 5.0000 & 2.5000 & 0.1250 & 21.7463 \\
\hline
\end{tabular}

Основні характеристики, отримані при навчанні та реалізації інформації, яка надходила, наведені в табл. 2.

Таблиця 2

\section{Результат роботи мережі}

\begin{tabular}{|c|c|c|c|c|}
\hline № & $\begin{array}{c}\text { Значення } \\
\text { ваг,од. }\end{array}$ & $\begin{array}{c}\text { Значення } \\
\text { ваг,од. }\end{array}$ & $\begin{array}{c}\text { Зсув, } \\
\text { од. }\end{array}$ & $\begin{array}{c}\text { Активність, } \\
\text { од. }\end{array}$ \\
\hline 1 & 8.3335 & 4.8169 & 21.2168 & 0.1281 \\
\hline 2 & 0.0133 & 4.6603 & 21.9113 & 0.1241 \\
\hline 3 & 6.2568 & 0.4926 & 22.4410 & 0.1211 \\
\hline 4 & 2.8521 & 4.4364 & 21.7848 & 0.1248 \\
\hline 5 & 7.3335 & 4.8169 & 21.5527 & 0.1261 \\
\hline 6 & 0.0133 & 4.6603 & 20.5124 & 0.1325 \\
\hline 7 & 8.2568 & 0.4926 & 22.6286 & 0.1201 \\
\hline 8 & 2.8521 & 84.4364 & 22.0736 & 0.1231 \\
\hline
\end{tabular}




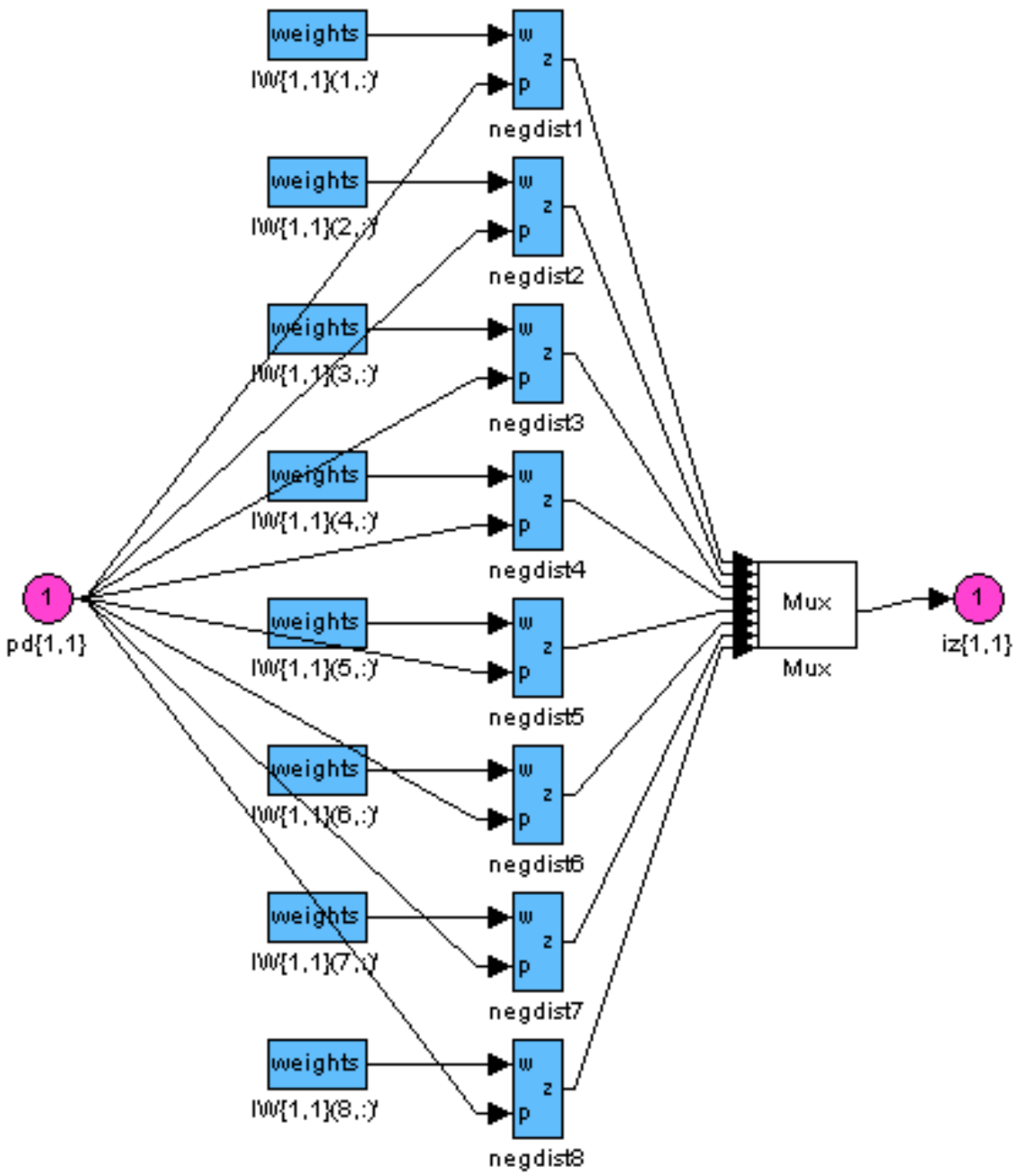

Рис. 1. Модель самоорганізаційної карти Кохонена , його ваг і зміщень

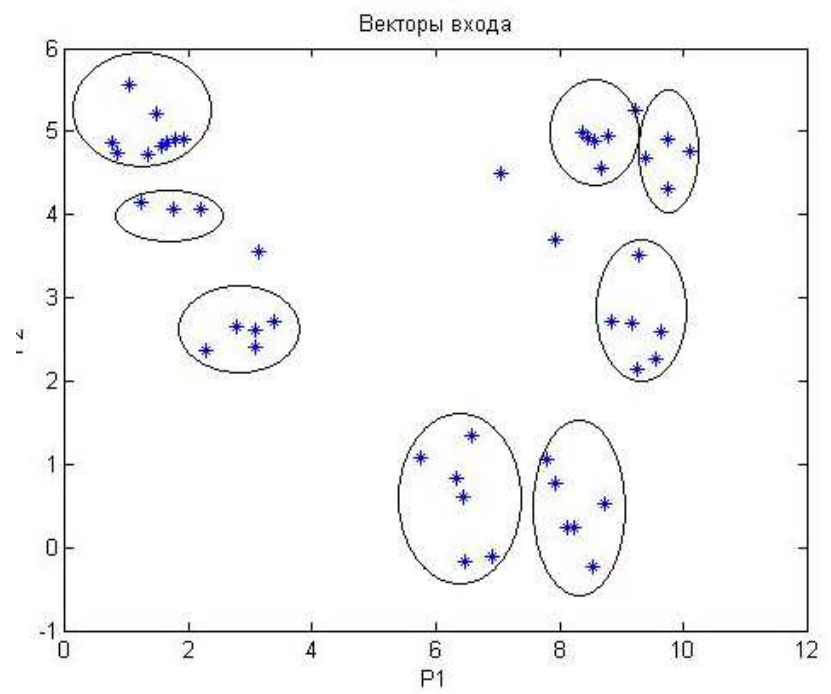

Рис. 2. Графік випадкових векторів на площині згрупованих в 8 кластерів
3 графіка видно, що центри кластеризації розподілилися у вісьмох областях, зміщення відхилилися в обидві сторони від вихідного значення в середньому на 21 од. так само, як i параметри активності нейронів.

Складність вхідного простору бралася в спрощеному вигляді в зв'язку з обмеженою кількістю обчислюваних ресурсів. Для імітації реальної вхідної послідовності слід проаналізувати обсяг вхідних потоків і визначити необхідний обчислювальний ресурс для даних потоків.

\section{Висновок}

У даній роботі була розглянута нейронна мережа СКК як когнітивний рівень в класифікації службових сигналів стандарту IEEE 802.22. Було побудовано імітаційну модель в середовищі розробки MATLAB. Результат даної роботи показав, що СКК здатна кластеризувати складні сигнали, що в свою чергу вирішує задачу, яка була поставлена. 
Лiтература

1. J. Mitola III and G. Q. Maguire Jr., "Cognitive Radio: Making Software Radios More Personal," IEEE Pers. Commun., vol. 6, no. 4, Aug. 1999. pp. 13-185

2. Ивлев А. А. Основы теории Бойда. Направления развития, применения и реализации. Монография. - Москва, 2008, 64 с.

3. Stevenson, C.; Chouinard, G.; Zhongding Lei; Wendong Hu; Shellhammer, S.; Caldwell, W.:«IEEE 802.22: The first cognitive radio wireless regional area network standard. Communications Magazine, IEEE». January 2009. pp. $130-138$.

4. R.V. Prasad, P. Pawelczak, J. Hoffmeyer and S. Berger, Cognitive functionality in next generation wireless networks: Standardization efforts," IEEE Commun. Mag., Apr. 2008, pp. 115-129.

5. D.E. Goldberg, Genetic Algorithms in Search, Optimization, and Machine Learning, Reading, MA: Addison-Wesley, 1989. pp. 215-221.

6. Свергунова Ю.О.Метод квазіортогонального частотного мультиплексування на піднесних частотах [Текст]: Ю.О. Свергунова, В.П. Лисечко, Д.О. Легка // Інформаційно-керуючі системи на залізничному транспорті. - 2015. - № 2. - С. 75-79

7. J. Mitola"Cognitive Radio Architecture: The Engineering Foundations of Radio XML", Wiley 2006, pp. 315-317.

8. H. Arslan (EditorH. Arslan (Editor), "Cognitive Radio, Software Defined Radio, and Adaptive Wireless Systems", Springer, pp. 211-217.

9. Q. Mahmoud "Cognitive Networks", Wiley 2007, Hardcover, pp. 57-66.

10. O. Mian, R. Zhou, X. Li, S. Hong, and Z. Wu, "A software-defined radio based cognitive radio demonstration over FM band," in Proc. International Conference on Wireless Communications and Mobile Computing, June 2009, pp. 495 - 499.

11. Боровиков B. Statistica. Искусство анализа данных на компьютере. Монография. Питер - 2003. C. 87-96.

12. Терехов С.А. Технологические аспекты обучения нейросетевых машин. Нейроинформатика - 2006. C. $155-156$.

13. S. Haykin, D. Thomson, and J. Reed, "Spectrum sensing for cognitive radio, Proceedings of the IEEE", vol. 97, no. 5, May 2009, pp. 849-877.

Лысечко В.П., Обиход Я.Я., Олефиренко Т.М. Исследование вероятностного распределения служебных сигналов в когнитивном радио. В статье рассматривается нейронная сеть в виде самоорганизующейся карты Кохонена как метод структурирования сервисных сигналов стандарта IEEE 802.22. Была рассмотрена нейронная сеть СКК как когнитивный уровень в классификации служебных сигналов стандарта IEEE 802.22. Результат данной работы показал, что СКК способна кластеризовать сложные сигналы, и, в свою очередь решает задачу, которая была поставлена.

Ключевые слова: когнитивное радио, радиочастотный ресурс, WiMAX, LTE, нейронная сеть (НC), сознательная карта Кохонена (СКК).

Lysechko V.P., Obikhod Y.Y., Olefirenko T.M. Research of probability distributions signaling in cognitive radio. The article discusses a neural network in the form of self-organizing Kohonen maps (SOKM) as a method of structuring the service signals of the standard IEEE 802.22. Examined the neural network of the SOKM as a cognitive level classification signaling standard IEEE 802.22. It was built simulation model considered in the development environment MATLAB. Implemented training Hebb rule is defined as a training sample 8 randomly-generated sequences. Hebb rule change provides connections in one direction only, which in this case could lead to a wrong determination of the values of the weights. To avoid this, the concept entered by smoothing function. The complexity of the input of the space was taken in a simplified way due to the limited amount of computing resources. To simulate a real input sequence should review the amount of the input stream and determine the appropriate computing resources for data flows. The result of this work showed that the SOKM is able to cluster complex signals, in turn solves the problem, which was staged.

Key words: cognitive radio, the radio resource, WiMAX, LTE, neural network, self-organizing Kohonen map (SOKM).

Рецензент д.т.н., професор Альошин Г.В. (УкрдУзТ)

Поступила 29.10.20152.

Лисечко Володимир Петрович, канд.техн.наук, доиент, доиент кафедри «Транспортний зв'язок», Украӥнський державний університет залізничного транспорту, м. Харків, Україна.

Обіход Ярослав Ярославович, програміст, «Softreview», м. Київ, Україна.

Олефіренко Тетяна Миколаӥвна, студентка, Український державний університет залізничного транспорту, м. Харків, Україна.

Lysechko V.P., PhD, docent of "Transport connection" Department, Ukrainian State University of Railway Transport, Kharkiv, Ukraine.

Obikhod Y.Y., programmer, «Soft-review», Kyiv, Ukraine. Olefirenko T.M., student, Ukrainian State University of Railway Transport, Kharkiv, Ukraine. 